\title{
Correspondence
}

\section{Soy feeding in infancy}

Sir,

I read Dr Taitz's annotation ${ }^{1}$ with interes t but would take issue with 3 of his 4 conclusions (the other being a statement of fact). 'Proved cows' milk protein intolerance should be treated with formulae consisting of protein hydrolysates'. Surely proved intolerance of any food should be treated by exclusion of that food and in the case of infants on predominantly milk diets substitution of a tolerated milk. Most infants unable to tolerate cows' milk can tolerate soy feeds, though a few cannot. Earlier Dr Taitz writes, 'Modern soy-based infant formulae are satisfactory feeds and there are no major problems in their use apart from expense'. Prices of soy milks and relevant protein hydrolysates (MIMS October 1982) are as follows:

$\begin{array}{ll}\text { Formula S Cow and Gate } & 450 \mathrm{~g} £ 1 \cdot 65 \\ \text { Prosobee (powder) } & 394 \mathrm{~g} £ 3.54(=450 \mathrm{~g} £ 4 \cdot 05) \\ \text { Velactin } & 454 \mathrm{~g} £ 2.99 \\ \text { Wysoy } & 500 \mathrm{~g} £ 1 \cdot 90(=450 \mathrm{~g} £ 1 \cdot 71) \\ \text { Nutramigen } & 454 \mathrm{~g} £ 7 \\ \text { Pregestimil } & 454 \mathrm{~g} £ 8 \cdot 01\end{array}$

Economy alone suggests that an infant intolerant of cows' milk (unless seriously ill) should be tried on a soy feed before considering protein hydrolysates.

'The indiscriminate use of soy formula for vague symptoms and signs not proved to be due to cows' milk intolerance is to be avoided'. Without diminishing the contribution of the immunologists, the most convincing evidence of any food intolerance is disappearance of the symptoms when the food is excluded. A trial of soy milk is the simplest and cheapest way of establishing cows' milk intolerance in the first instance.

'Soy feeds should not be freely available without prescription'. Why should the NHS pay for infant feeds that cost only marginally more than ordinary infant milks?

\section{Reference}

1 Taitz L S. Soy feeding in infancy. Arch Dis Child 1982; 57: 814-5.

R W SMITHELLS Department of Paediatrics and Child Health, University of Leeds, 27 Blundell Street, Leeds LSI 3ET

Sir,

I read with interest Dr Taitz's annotation on soy feeding, ${ }^{1}$ a much disputed topic amongst paediatricians. Much of the text made sound sense but I found myself in disagreement with his conclusions.

His first regarding atopy is straight forward and most of us, I expect, find a few patients who improve on a soy based diet. His second relates to the self limiting syndrome of diarrhoea and malnutrition which improves on a cows' milk free diet. Dr Taitz feels these infants need an expert evaluation to prove the diagnosis. Does he mean a paediatric gastroenterologist and does he mean a jejunal biopsy is essential? With an incidence rate of $0.5 \%$ there will be about 40 new cases in Sheffield each year, and most of these are managed by general paediatricians. Most of those I have spoken to no longer feel justified in performing jejunal biopsies before starting such children on a cows' milk free diet. Dr Taitz may argue that the diagnosis has not then been proved, but in a self limiting condition this is surely not necessary. If the condition of the infant improves it may not even be necessary to admit him to hospital and a single positive challenge perhaps a month later seems quite adequate evidence to keep the child off cows' milk for several months before trying to re-establish him. I follow Dr Taitz's arguement that soy protein may not be the ideal substitute because of reports of soy intolerance, but it is very much cheaper than formulae containing protein hydrolysates. In clinical practice most infants fed soy formulae improve symptomatically and grow. If they don't, then that may be the time to reconsider the diagnosis or try a formula containing protein hydrolysates.

Dr Taitz's third conclusion relates to the use of soy protein for vague symptoms. There may be a danger of over diagnosis of allergic disorders with subsequent long term effects on child rearing, and by applying Dr Taitz's strict criteria for diagnosis many families may go through weeks or months of unnecessary suffering. Dr Taitz says the key in the satisfactory home is the centile chart. What is the key in the unsatisfactory home where breast feeding is less common and there may be many psychosocial factors contributing to the infants failure to thrive? One many not be able to alleviate easily many of these factors but coincidental cows' milk intolerance may be missed. There is evidence that some cases of colic are related to cows' milk intolerance ${ }^{2}$ and I believe that when faced with an infant with excessive crying, vomiting, wind or colic a trial off milk is justified, after a careful history and examination to exclude other causes. While the soy preparations cost a fraction of the price of those containing protein hydrolysates, many may wish to use the former.

Perhaps to end rather cynically, if the modern soy based infant formulae are as Dr Taitz says satisfactory feeds and are no more, and some may say less, allergenic than cows' milk based feeds, what is the justification for saying that the former rather than the latter should be only available on prescription?

\section{References}

1 Taitz L S. Soy feeding in infancy. Arch Dis Child 1982; 57: 814-5. 
2 Lothe L, Lindberg T, Jakobsson I. Cows' milk formula as a cause of infantile colic: a double blind study. Pediatrics 1982; 70: 7-10.

\section{R N MiLes \\ Northern General Hospital, Herries Road, Sheffield S5 $7 A U$}

Sir,

I would like to take issue with Dr Taitz's recommendations with regard to the use of soy based infant milk formulae. ${ }^{1}$ I do not think Dr Taitz can have any idea how common gastrointestinal symptoms caused by milk intolerance are. This is because he demands 'partial or subtotal villous atrophy' and failure to thrive. I have performed many biopsies on children with this condition and I find that it is more often a cause of chronic gastrointestinal symptoms in children who are thriving and have normal villous morphology. I realise there is the problem of patchy morphological change, but in practice the villi are essentially normal in the thriving milk intolerant child. Sometimes colic is the predominant symptom, but this is not 'evening colic'-these infants get colic after every feed. Usually the children grow out of their symptoms, but there is much misery on the way and it is not adequate to say 'the diagnosis of this condition should not be made without careful evaluation by an expert in the field'. Many tests can be helpful in the diagnosis of milk intolerance, ie radioallergosorbent test, milk antibodies, jejunal biopsy etc, but I think the final arbiter is still the milk challenge, preferably more than one if the mother will permit this.

Soy protein is probably just as allergenic as cows' milk protein, but since it is introduced later, ie as treatment, it is not common in practice to get a second intolerance to the soy protein, though this has to be watched for. Its palatability is superior to that of the hydrolysates which is an important consideration especially with the older infants. Now that cheap soy based formulae are available and are known to be nutritionally satisfactory the management of these infants is much easier.

If an unweaned infant has symptoms due possibly to milk intolerance and is failing to thrive he should be referred to a consultant paediatrician for further evaluation. If the infant has such symptoms but is thriving, then the feed should be changed for 2 weeks to a soy based formula under a doctor's supervision (general practitioner or consultant). If there is no improvement the child should be put back on the original formula. If there is improvement or the situation is doubtful, then milk intolerance is possible and the infant should be referred to a consultant paediatrician at that point if the GP has begun the trial of the soy based formula. After one month a cows' milk challenge should be given preceded by a lactose tolerance test. Some cases are very clear and one challenge is enough to make the diagnosis; others are more difficult and two challenges or other tests may be necessary.

We are still waiting for a good test for milk intolerance comparable with the jejunal biopsy in coeliac disease or the sweat test in cystic fibrosis, but I fear we may wait a long time. Considering the variation in symptoms and the differing response times after milk challenge, there may be several immunological mechanisms at work.

\section{Reference}

1 Taitz L S. Soy feeding in infancy. Arch Dis Child 1982; 57: $814-5$.

J F B Dossetor Paediatric Department, The Queen Elizabeth Hospital, Gayton Road, King's Lynn, Norfolk PE30 4ET

\section{Dr Taitz comments:}

The three letters written in response to my annotation present powerful arguments against my conclusions. On reflection, however, I do not believe that they fundamentally weaken the case against widespread use of soy feeds, or rather and more importantly, the over diagnosis of cows' milk intolerance.

Babies who fail to thrive warrant jejunal biopsy before beginning treatment. Proved cows' milk intolerance with failure to thrive and jejunal mucosal atrophy warrants optimal treatment. This condition is rare and the use of hydrolysed formula seems justified by the well documented reports cited in my review of soy intolerance including anaphylaxis which may occur particularly in these infants. Jejunal changes in the absence of failure to thrive but with gastrointestinal symptoms are in the same category.

Infants who have symptoms which may be due to milk intolerance but who are thriving and show no evidence of intolerance such as positive RAST or raised IgE values continue to pose problems. Most children who cry, are restless, have wind, colic and possetting but are thriving, do not have cows' milk intolerance and become normal in time. My annotation is intended as a corrective to a growing use of soy feeds as reflex action.

In an atmosphere of growing anxiety-some might say hysteria-about food allergies, we have some responsibilities not to add unnecessarily to the trend. Hence my plea for careful evaluation of all babies before diagnosing milk intolerance. The mere improvement of a symptom on changing feeds in itself proves nothing as there is such a high probability of spontaneous improvement or a placebo effect. Symptoms which are highly subjective in both nature and severity, cannot be confirmed by investigation, are self limiting, and may be due to multiple causes, are easily misdiagnosed with delay in identification of the basic problem. I have had to deal recently with the potentially serious consequences of maternal depression treated by changing the baby's feed from breast to cows' milk formula to soy. Even allowing Dr Miles's generous calculation of incidence, a general practitioner is likely to see one case of cows' milk intolerance in three years. Even paediatricians are not likely to encounter more than five cases a year. These considerations argue for circumspection in ascribing symptoms to milk intolerance with consequent over investigation, medical 